\title{
Linfoma endobronquial ALK-1 positivo, primario de pulmón. Informe de un caso
}

\author{
Fulgencio Guillermo Díaz-Orrostieta, $\bowtie$ José Miguel Martínez y Martínez.
}

Centro Médico ABC, Ciudad de México.

Trabajo recibido: 28-II-2014; aceptado: 01-IV-2015

\begin{abstract}
RESUMEN. El linfoma pulmonar primario es muy raro, mientras que la presentación extranodal representa del 25 al $50 \%$ de los casos de linfoma no Hodgkin. El pulmonar primario sólo representa del 3 a $4 \%$ de linfoma no Hodgkin y del 0.5 a $1 \%$ de las neoplasias primarias pulmonares. La prevalencia de linfoma pulmonar dentro de los tumores de pulmón es del 13\% en adultos. La presentación endobronquial como manifestación del linfoma primario pulmonar sólo ocurre en el $0.4 \%$ de los casos. Se define como linfoma pulmonar primario a la proliferación atípica linfoidea de uno o ambos pulmones en un paciente con indetectable enfermedad extrapulmonar. Se informa un caso de linfoma primario anaplásico endobronquial de células grandes de pulmón, ALK-1 positivo, que es un marcador pronóstico y específico de esta entidad.
\end{abstract}

Palabras clave: Linfoma anaplásico de células grandes, ALK-1 positivo, pulmón.

ABSTRACT. The primary pulmonary lymphoma is very rare, while the extranodal presentation represents the 25 to $50 \%$ of the cases of nonHodgkin's lymphoma. The primary pulmonary commitment represents only 3 to $4 \%$ of non-Hodgkin's lymphoma and 0.5 to $1 \%$ of the primary pulmonary neoplasms. The prevalence of pulmonary lymphoma within the lung tumors is $13 \%$ in adults. Endobronchial presentation as a manifestation of primary pulmonary lymphoma, only occurs in $0.4 \%$ of the cases. Is defined as primary pulmonary lymphoma, to the proliferation of atypical lymphoid one or both lungs in a patient with undetectable extrapulmonary disease. We report a case of anaplastic lymphoma endobronchial large cell lung primary, ALK-1 positive, which is a prognostic marker of this entity.

Key words: Anaplastic large cell lymphoma, ALK-1 positive, lung.

\section{INTRODUCCIÓN}

El linfoma anaplásico de células grandes (LACG), también llamado linfoma Ki-1, es un linfoma morfológica e inmunológicamente distinto. Fue descrito originalmente por Stein et al. en 1985. Este tipo de linfoma no Hodgkin se caracteriza por ser Ki-1 (CD30) positivo con expresión de otros antígenos de activación linfoide no específicos de esta entidad, porque se han identificado en otras neoplasias linfoides y no linfoides. ${ }^{1}$ A partir de la clonación de este gen se identifican tres entidades clínicas como factor pronóstico: linfoma anaplásico sistémico ALK (+), linfoma anaplásico sistémico ALK (-) y linfoma anaplásico cutáneo. En la actualidad, el criterio para linfoma primario de pulmón es demostrar la ausencia de compromiso extraparenquimatoso al momento del diagnóstico o en un período posterior de tres meses. ${ }^{2,3}$

Presentamos un caso de linfoma anaplásico de células grandes (Ki-1+) primario de pulmón, con presentación clínica atípica cuya localización fue endobronquial.

\section{CASO CLÍNICO}

Paciente masculino de 37 años, con antecedentes de asma durante la infancia; presentó un neumotórax derecho espontáneo primario hace 15 años, tratado con colocación de sonda pleural por cuatro días, secundario a bulas congénitas. Hace cinco años funduplicatura de Nissen $\left(360^{\circ}\right)$ sin complicaciones. Previo a su ingreso al hospital presentó disnea de grandes a medianos esfuerzos, sibilancias audibles a distancia, motivo por el que se le realiza radiografía de tórax en proyección posteroanterior (figura 1), siendo reportada como normal; se inicia tratamiento con bromuro de ipatropio/salbutamol y ceftriaxona, con mejoría parcial del cuadro. A los tres días de haber iniciado el tratamiento presenta tos con escasos hemoptoicos intermitentes, situación por la que asiste a urgencias en donde se le realiza tomografía simple de tórax (figura 2) con presencia de una masa a nivel del bronquio principal derecho, así como presencia de adenomegalias mediastinales. 
Por los hallazgos mencionados y como parte del protocolo se le realizó PET-CT (figura 3) encontrando una masa en bronquio principal derecho con actividad metabólica de 12 SUV. Se realizó una broncoscopia con los siguientes hallazgos: en la emergencia del bronquio principal derecho a $1.5 \mathrm{~cm}$ de la carina principal, había una lesión (figura 4) que abarcaba más del $90 \%$ de la luz del bronquio principal derecho. La lesión contaba con bordes bien definidos, despulidos, blanquecinos y fácilmente sangrantes (figura 5). Se tomaron biopsias por pinza, cepillado y lavado bronquial. La citología de lavado y cepillado bronquial fue positiva para células neoplásicas malignas que favorecen a linfoma (figura 6), las biopsias bronquiales reportaron infiltración por linfoma anaplásico de células grandes, ALK-1 positivo (CD45RO+/ EMA+/CD30+) (figura 7), la biopsia de médula ósea negativa a infiltración, serología para $\mathrm{VIH}$ negativa. Se estableció un esquema de quimioterapia a base de ciclofosfamida, hidroxidoxorrubicina, vincristina y prednisona. La consulta de control a los tres meses del diagnóstico con resultado de PET-CT de control reportó masa en bronquio derecho con actividad metabólica de 3 SUV, no evidenció otras lesiones con actividad metabólica. Se continuó seguimiento por consulta externa.

\section{DISCUSIÓN}

Cadranel et al. ${ }^{4}$ establecen que el compromiso pulmonar por linfoma puede manifestarse de tres formas:

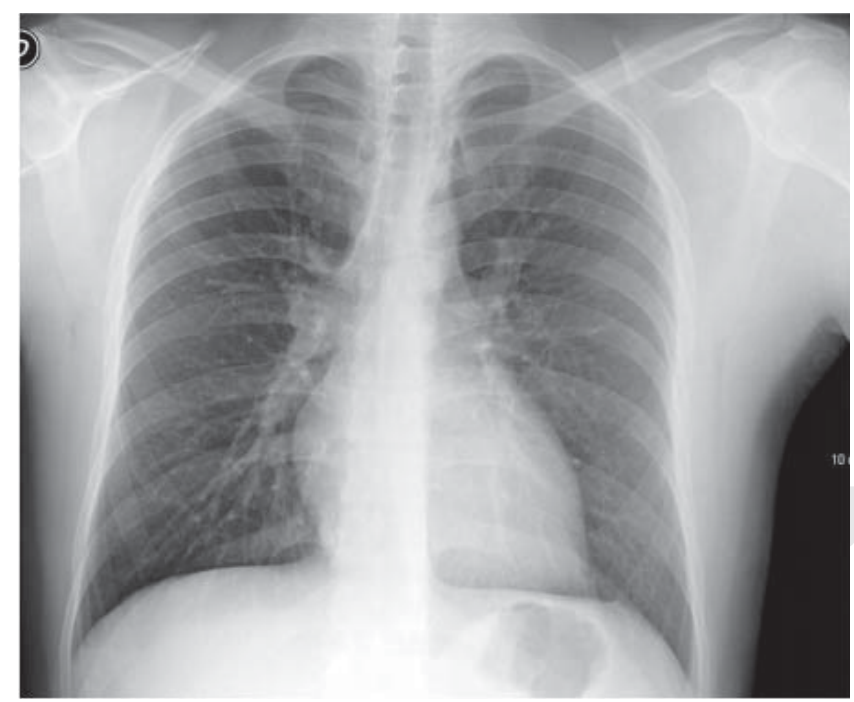

Figura 1. Radiografía de tórax en proyección posteroanterior, no muestra lesiones de nódulos o masas, ni ensanchamiento mediastinal. Se reporta el estudio como normal.
1) por diseminación hematógena de la neoplasia, 2) por continuidad del linfoma en nódulos mediastinales o hiliares y 3) por linfoma pulmonar primario. Las dos primeras situaciones son el resultado de una progresión a un desorden directamente relacionado al linfoma $y$, en efecto, deben interpretarse como metástasis hematógenas de la enfermedad. La tercera situación del linfoma pulmonar primario, es definida por una proliferación atípica linfoidea de uno o ambos pulmones en un paciente con indetectable enfermedad extrapulmonar. Tal como es el caso que se presenta, en donde sólo se documentó la masa del bronquio principal derecho, con resultado de biopsia de médula ósea negativo y con dos estudios de PET-CT.

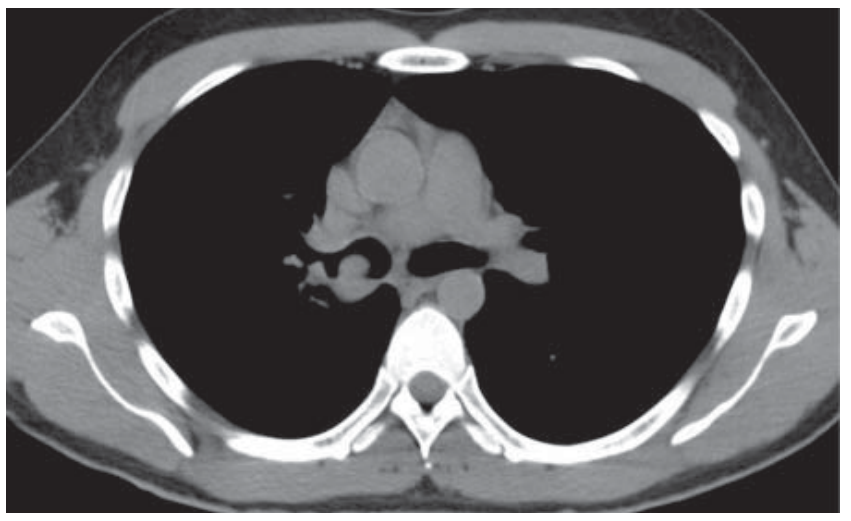

Figura 2. Tomografía de tórax simple con hallazgo de masa localizada en el bronquio principal derecho, sin evidencia de atelectasia, ni broncograma. Adenomegalias mediastinales menor de $2 \mathrm{~cm}$ de diámetro. Parénquima pulmonar sin datos de nódulos o masa.

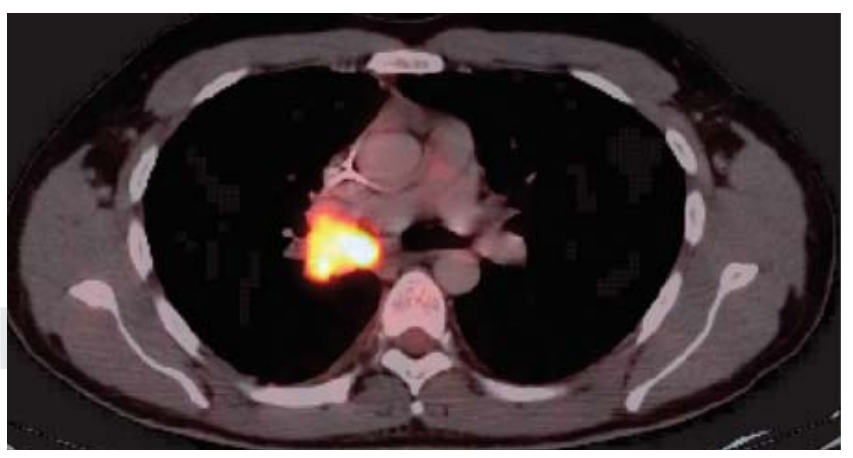

Figura 3. Estudio de medicina nuclear tipo PET-CT, en donde sólo se aprecia actividad metabólica caracterizada por 12 SUV en la masa localizada en el bronquio principal derecho. No presenta actividad metabólica en alguna otra región del estudio. 


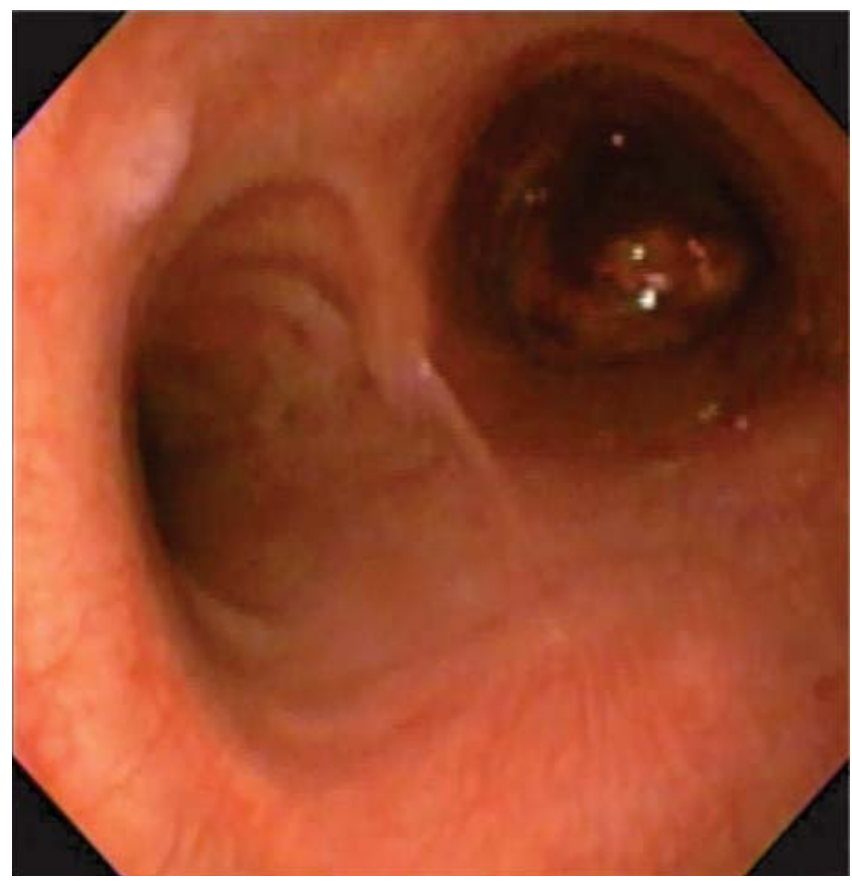

Figura 4. Imagen de videobroncoscopia en donde se aprecia anatómicamente la carina principal, en la emergencia del bronquio principal derecho, con lesión que protruye en el $90 \%$ de la luz del bronquio.

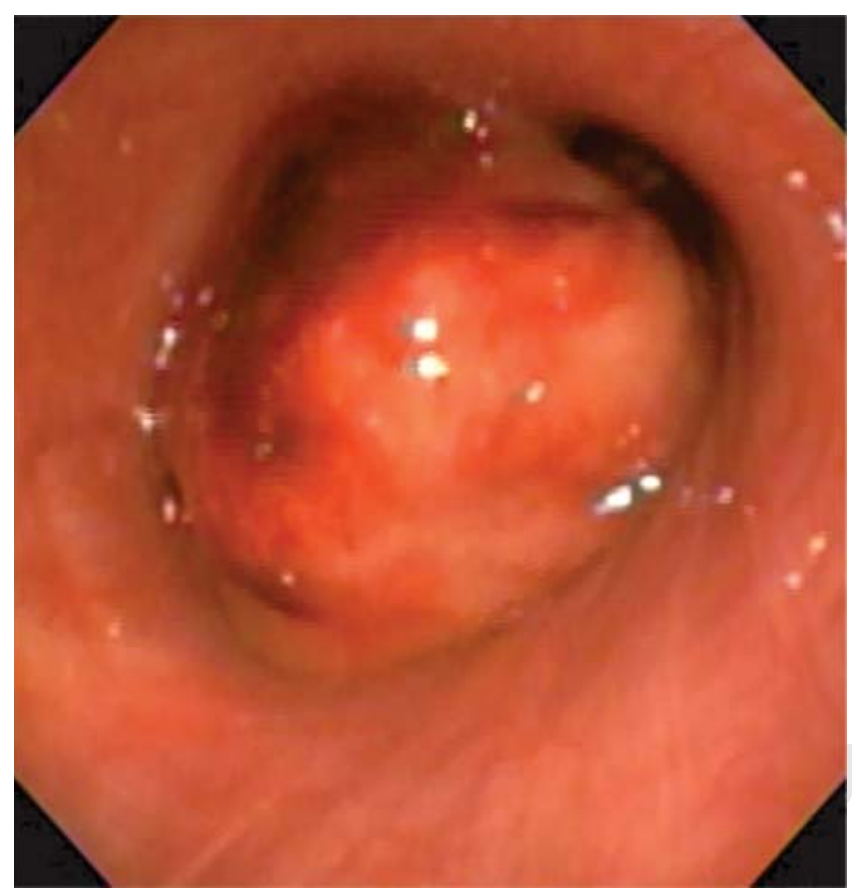

Figura 5. Acercamiento de la lesión bronquial, en donde se aprecia que se trata de una lesión redondeada, de bordes regulares, despulida con irregularidad de la mucosa circundante de la lesión compatible con infiltración de la misma, la cual sangra fácilmente.

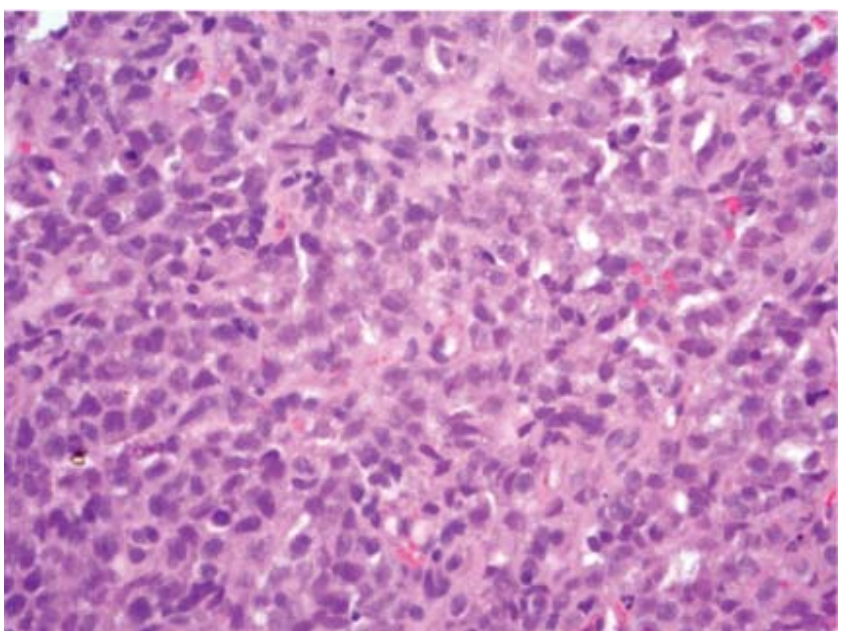

Figura 6. Corte histológico, se observan células de núcleos redondeados claros (vesiculosos), con cromatina marginada (membrana nuclear gruesa) y nucléolos destacados. Se observan también células retraídas con tendencia a la homogeneización (apoptosis). Tinción de hematoxilina-eosina.

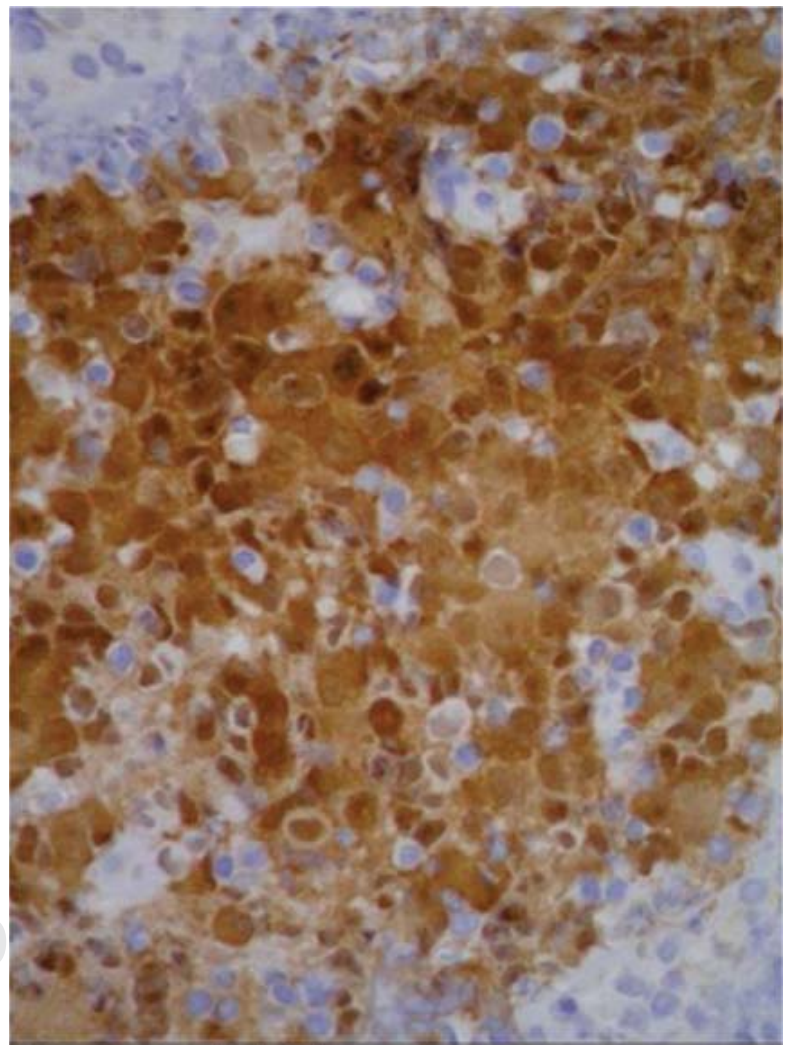

Figura 7. Inmunohistoquímica de linfoma de células grandes, presentan coexpresión de los siguientes marcadores en el citoplasma (CD45RO+/EMA+/CD30+). Para considerarlo anaplásico presentan positividad en el citoplasma del marcador ALK-1 (color café en la cromatina del citoplasma). 
Bazot et al. ${ }^{5}$ en su serie establecieron que los hallazgos radiológicos habituales en el linfoma primario pulmonar se aprecian como una ocupación alveolar en el $50-90 \%$ de los casos, con un diámetro menor de $5 \mathrm{~cm}$ y con un borde bien delimitado; la serie reporta hasta un $50 \%$ de los casos con presencia de broncograma aéreo. La tomografía computada, estudio que cuenta con mayor sensibilidad, ha demostrado que las lesiones son bilaterales (60-70\%) y múltiples (70-77\%). Menos del $10 \%$ de los pacientes tienen opacidades reticulonodulares difusas bilaterales, atelectasias o derrame pleural. En nuestro estudio, en la tomografía de tórax y como complemento del PET-CT, sólo se definió la presencia única de una masa en bronquio principal derecho.

En otra serie de pacientes con VIH/SIDA Corti et al. ${ }^{6}$ establecieron que el linfoma pulmonar primario es muy raro, mientras la presentación extranodal representa del 25 al $50 \%$ de los casos de linfoma no Hodgkin. El compromiso pulmonar primario sólo representa del 3 a $4 \%$ de linfoma no Hodgkin y sólo del 0.5 a $1 \%$ de las neoplasias primarias pulmonares. El caso que presentamos es VIH negativo y sin evidencia de otras lesiones. La prevalencia de linfoma pulmonar dentro de los tumores de pulmón es del $13 \%$ en adultos. ${ }^{7}$

Por su parte, Solomonov et al. ${ }^{8}$ en una serie de ocho casos recopilados entre 1998 y 2005, reportaron rangos de edad de 46 a 81 años; determinaron que sólo el $1.1 \%$ de lesiones endobronquiales corresponde a linfoma (con respecto al diagnóstico de otros tumores pulmonares), y la presentación endobronquial como manifestación del linfoma primario pulmonar sólo ocurre en el $0.4 \%$ de los casos. En nuestro caso, la edad del paciente fue de 37 años.

Shiota et al. ${ }^{9}$ describieron mayor expresión del ALK en los pacientes jóvenes con pronóstico favorable y supervivencia a cinco años de $71 \pm$ $6 \%$, a diferencia de los casos ALK- que es de $15 \pm$ $11 \%$. Los resultados de nuestro caso fueron ALK1 positivos. Nosari et al. ${ }^{10}$ en un estudio realizado en una serie de pacientes con síndrome de inmunodeficiencia adquirida con LACG, CD30 + (10 pacientes) y CD30- (28 pacientes), concluyeron que la afectación pulmonar es más frecuente (40 vs. $21 \%$ ) en aquellos pacientes con HIV+ CD30. Sin embargo, la presentación primaria del LACG en pulmón es una entidad rara con frecuencia menor a $1 \%$ de todos los linfomas, siendo la mayoría de estos linfomas no Hodgkin de bajo grado de malignidad de estirpe B. ${ }^{11}$
En la literatura sólo se identificaron 8 casos publicados; 5 de los cuales fueron informados por Rush, uno por Chott et al., ${ }^{12}$ un caso por Beltrán y un caso por Chadburn $\mathrm{A}$ et al., ${ }^{13}$ este último asociado a HIV+.

\section{CONCLUSIÓN}

El interés de presentar el siguiente caso fue debido a que el linfoma anaplásico primario pulmonar ALK-1 positivo, con lesión única endobronquial es una presentación poco frecuente y cuyo diagnóstico fue realizado por broncoscopia.

\section{REFERENCIAS}

1. Rush WL, Andriko JA, Taubenberger JK, et al. Primary anaplastic large cell lymphoma of the lung: a clinicopathologic study of five cases. Mod Pathol 2000;13(12):1285-1292.

2. Beltrán BS, de Tomás LM, Ferreras FP. Linfoma no Hodgkin pulmonar primario anaplásico de células grandes $\mathrm{Ki}-1$ positivo. Estudio de un caso y revisión de la literatura. An Med Interna (Madrid) 2001;18(11):587-590.

3. Stein H, Foss HD, Dürkop H, et al. HCD30(+) anaplastic large cell lymphoma: a review of its histopathologic, genetic, and clinical features. Blood 2000;96(12):36813695.

4. Cadranel J, Wislez M, Antoine M. Primary pulmonary lymphoma. Eur Respir J 2002;20(3):750-762.

5. Bazot M, Cadranel J, Benayoun S, Tassart M, Bigot JM, Carette MF. Primary pulmonary AIDS-related lymphoma: radiographic and CT findings. Chest 1999;116(5):12821286.

6. Corti M, Villafañe MF, Trione N, Schtirbu R, Narbaitz M. Primary pulmonary AIDS-related lymphoma. Rev Inst Med Trop Sao Paulo 2005;47(4):231-234.

7. Maturen KE, Blane CE, Strouse PJ, Fitzgerald JT. Pulmonary involvement in pediatric lymphoma. Pediatr Radiol 2004;34(2):120-124.

8. Solomonov A, Zuckerman T, Goralnik L, Ben-Arieh Y, Rowe JM, Yigla M. Non-Hodgkin's lymphoma presenting as an endobronchial tumor: report of eight cases and literature review. Am J Hematol 2008;83(5):416-419. doi: 10.1002/ajh.21112.

9. Shiota M, Nakamura S, Ichinohasoma R, et al. Anaplastic large cell lymphomas expressing the novel chimeric protein $580 N P M / A L K$ : a distinct clinicopathologic entity. Blood 1995;86(5):1954-1960.

10. Nosari A, Cantoni S, Oreste P, et al. Anaplastic large cell (CD30/Ki-1+) lymphoma in HIV+ patients: clinical and pathological findings in a group of ten patients. Br J Haematol 1996;95(3):508-512.

11. Menárguez J, Carrión JR. Linfomas pulmonares. Med Clin 1995;105:301-302. 
12. Chott A, Kaserer K, Augustin I, et al. Ki-1-positive large cell lymphoma. A clinicopathology study of 41 cases. Am J Surg Pathol 1990;14(5):439-448.

13. Chadburn A, Cesarman E, Jagirdar J, Subar M, Mir RN, Knowles DM. CD30 (Ki-1) positive anaplastic large cell lymphoma in individuals infected with the human immunodeficiency virus. Cancer 1993;72(10):3078-3090.

\section{$\triangle$ Correspondencia:}

Dr. Fulgencio Guillermo Díaz Orrostieta

Consultorio 408, Hospital ABC Observatorio. Sur 132

Núm. 108, Colonia Las Américas, Delegación Álvaro Obregón, 01120, México, D.F.

Correo electrónico: drful@ hotmail.com

Los autores declaran no tener conflicto de intereses. 